\title{
Application of Carbon Fiber Materials in Water Conservancy Project
}

\author{
Yongxia TAO \\ Yellow River Conservancy Technical Institute \\ Engineering Research Center of Small Watershed \\ Conservancy University of Henan Province \\ Kaifeng, China \\ E-mail: hhtaoyx@163.com
}

\begin{abstract}
The types of carbon fiber materials used in the engineering field were summarized, and the main characteristics of carbon fiber material, high strength, high elastic modulus, small density and high specific strength were summarized. According to the excellent properties of carbon fiber material and the characters of conservancy projects, the paper introduces the application of carbon fiber material in water conservancy engineering reinforcement, and points out the important work that should be carried out in the near future of carbon fiber materials in the field of water conservancy project.
\end{abstract}

Keywords-carbon fiber; CFRP; reinforcement; water conservancy project Introduction

\section{INTRODUCTION}

As is known, concrete is a brittle material with poor ductility and crack resistance (its tensile strength is about $7 \% \sim 14 \%$ of compressive strength). Reinforced concrete composite as well as fiber concrete composite all reflects the wishes to improve the performance requirements of the concrete. Carbon fiber material, whose density is about $1 / 4$ of steel and tensile strength is far higher than that of steel, is a new material with excellent mechanical properties. Its tensile strength is more than $3500 \mathrm{MPa}$, about 8 times of that of steel (tensile strength of HRB335 steel for $455 \mathrm{MPa}$ ). The tensile elastic modulus of CFRP is 230 430GPa, higher than that of steel. If specific strength is defined as the ratio of material intensity and density, it is not difficult to see that the specific strength as well as the specific modulus of CFRP is far greater than that of steel. For the material, the higher the specific strength, the lighter the dead weight of the structural element of which is made these materials, and the higher the specific modulus, the bigger the stiffness of the corresponding structural element. Therefore, the prospect of carbon fiber is broad in the field of engineering. Carbon fiber materials have been successfully applied in the military industry, automobile industry and other fields, and then develop into the field of civil engineering as structural repair and reinforcement and so on. There are nearly 40 years of history of reinforced concrete structures in hydraulic engineering using carbon fiber materials in repairing and reinforcing defects (such as concrete cracks, leakage, etc.), mainly for reinforcement of concrete cracks, leakage of dam; repair and reinforcement of pier and breast wall; maintenance of pipework and tunnel; reinforcement deficiency of powerhouse, etc [1]. Carbon fiber material is widely used in engineering field because of its high tensile

\author{
Yakun ZHANG \\ Yellow River Conservancy Technical Institute \\ Engineering Research Center of Small Watershed \\ Conservancy University of Henan Province \\ Kaifeng, China \\ E-mail: 306533687@qq.com
}

strength, light weight, corrosion resistance and so on. Based on the summary of relevant literature, this paper summarizes the application of carbon fiber materials in the reinforcement of hydraulic engineering construction.

\section{CARBON FIBER MATERIAL}

Carbon fiber materials used in engineering field include carbon fiber (referred to as CF), carbon fiber reinforced plastic (referred to as CFRP), carbon fiber reinforced polymer laminate (referred to as CFRP sheet), carbon fiber laminate (referred to as CFL), carbon fiber sheet, carbon fiber reinforced bar, etc.

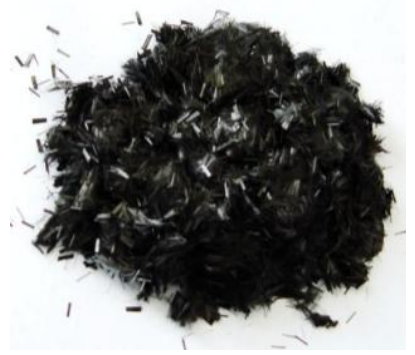

(a). Carbon fiber(a)

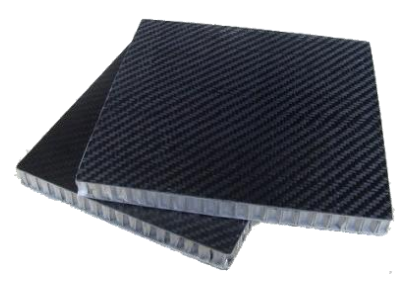

(c). Carbon fiber boards

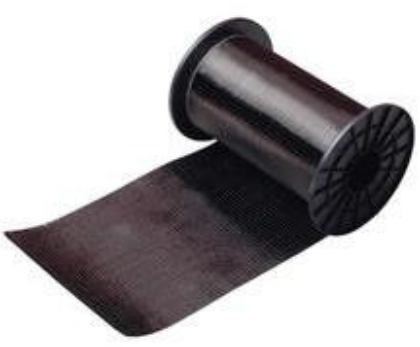

(b). Carbon fiber cloth/laminate

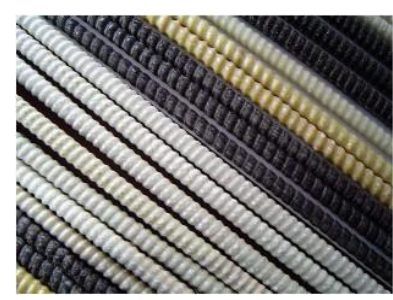

(d). Carbon fiber reinforced plastic bars
Figure 1. Carbon fiber materials

\section{A. Classification of Carbon Fiber Materials}

According to different mechanical properties, carbon fiber can be divided into ultra-high strength carbon fiber carbon fiber, high strength carbon fiber, ultra high modulus carbon fiber and high modulus carbon fiber. The tensile strength of ultra-high strength carbon fiber is over $4000 \mathrm{MPa}$, of high strength carbon fiber is between $2400 \sim 3000 \mathrm{MPa}$. The stretch elasticity modulus of ultra-high modulus carbon fiber is between 380 640GPa and of high modulus carbon fiber is generally between 270 320GPa. 
According to different raw materials, carbon fiber can be divided into PAN carbon fiber, asphalt carbon fiber and viscose rayon carbon fiber. These fibers, mainly made of element carbon, are made of master batch fibers, which are carbonized at high temperature. The indexes of the three main physical and mechanical performances of carbon fibers are listed in Tab. 1.

TABLE I. MAIN PHYSICAL AND MECHANICAL PROPERTIES OF 3 CARBON FIBER MATERIALS

\begin{tabular}{|l|l|l|l|l|}
\hline Category & \multicolumn{1}{|c|}{$\begin{array}{c}\text { Tensile } \\
\text { Strength } \\
(\mathbf{M P a})\end{array}$} & $\begin{array}{c}\text { Stretch } \\
\text { elasticity } \\
\text { modulus } \\
(\mathbf{G P a})\end{array}$ & $\begin{array}{c}\text { Density } \\
(\mathbf{g} / \mathrm{cm})\end{array}$ & $\begin{array}{c}\text { Percentage } \\
\text { elongation } \\
(\%)\end{array}$ \\
\hline $\begin{array}{l}\text { PAN } \\
\text { carbon } \\
\text { fiber }\end{array}$ & $>3500$ & $>230$ & $1.76 \sim 1.94$ & $0.6 \sim 1.2$ \\
\hline $\begin{array}{l}\text { Asphalt } \\
\text { carbon } \\
\text { fiber }\end{array}$ & 1600 & 379 & 1.7 & 1.0 \\
\hline $\begin{array}{l}\text { viscose } \\
\text { rayon } \\
\text { carbon } \\
\text { fiber }\end{array}$ & $2100 \sim 2800$ & $414 \sim 552$ & 2.0 & 0.7 \\
\hline
\end{tabular}

\section{B. Main Properties of Carbon Fiber Materials}

High mechanical stretch. As shown in Table 1 the tensile strength is above $1600 \mathrm{MPa}$, which is much higher than that of steel.

Low density and high specific stretch. The density of carbon fibers is between $1.76 \sim 1.80 \mathrm{~g} / \mathrm{cm}^{3}$ and of steels are generally $7.9 \mathrm{~g} / \mathrm{cm}^{3}$. Compared to steel, carbon fiber materials are higher in mechanical stretch and modulus, lower in density. So specific strength and specific modulus of carbon fibers are far higher than that of steel.

High temperature resistance and good low temperature resistance. In the low temperature of $-180^{\circ} \mathrm{C}$, the steel will become more brittle than glass while the carbon fiber material is still very soft. This property of carbon fiber materials makes them to have great performance in low temperature environment.

High corrosion resistance. Carbon fiber materials are nonmetals, which will not rust. Therefore, they can completely solve the problem of corrosion of steel in reinforced concrete if reasonably used.

Good acid resistance. Carbon fiber materials are resistant to concentrated hydrochloric acid, phosphoric acid, sulfuric acid, benzene, acetone and other medium erosions.

Small thermal expansion coefficient and large thermal conductivity.

\section{APPLICATIONS OF CARBON FIBER IN REINFORCING AND STRENGTHENING WATER CONSERVANCY PROJECT}

\section{A. Carbon Fiber as Reinforced Material for Hydraulic Concret}

Under certain conditions, the carbon fiber reinforced concrete (CFRC) is used as concrete by adding a certain amount of carbon fiber. The ultimate tensile strength and flexural strength of CFRC is 6 12 times higher than ordinary concrete; the strain capacity of the bending toughness and tension was 15 20 times higher than ordinary concrete; however, its mass is only half of the ordinary concrete. The incorporation of fibers not only strengthens the concrete matrix, but also significantly improves the crack resistance and toughness of concrete. At the same time, it can improve the performance of concrete seepage prevention etc. For example, the barrage of Baixi Reservoir in Ningbo, the reinforced concrete facing rock fill dam Zhejiang [2][3]. It had been found 21 cracks with width exceed $0.15 \mathrm{~mm}$ ( 8 of them with the crack width exceed $0.2 \mathrm{~mm}$ ) after the firststage facing project. For concrete facing rock fill dam, the cracks would increase the leakage loss, reduce project benefits, reduce the durability of concrete dam, lead to corrosion of reinforced panel crack, all of which would seriously affected the normal use of the project and its service life. The second-stage concrete project of Baixi Reservoir located in intertidal zone, where is affected by harsh environmental conditions such as cold waves in winter and strong winds. In order to improve the concrete durability of the dam project, after research, the participation of all parties jointly decided to solve the facing cracks issues in the second-stage project of Baixi Reservoir by fiber concrete. It was proved in practice that adding of fiber can reduce about $8 \%$ of concrete drying shrinkage, about $50 \%$ cracking index, effectively improve about $9 \%$ of the ultimate tensile strain, reduce about $10 \%$ of elastic modulus, improve $40 \%$ of the flexural toughness coefficient and increase the frost resistance grade from D100 to D200. It improves the deformation performance of concrete and its durability. The concrete gravity dam in Daheiting Reservoir, Qianxi, Hebei Province, uses CFRC concrete to reinforce overflow surface [4]. Compare the overflow surface repaired with fiber mesh and the unrepaired, regardless of the concrete strength, the overflow surface without fiber has a lot of mesh cracks. For the same and different strength concrete overflow surface, the number of cracks is greatly reduced, $90 \%$ for average, after mixing up fiber network, which fully shows that the fiber network plays an important role in reducing the cracks in the overflow surface. CFRC concrete also achieved good results in the spillway section of Three Gorges Project [5].

\section{B. Carbon Fiber Replacing Steel to Improve Crack Resistance and Corrosion Resistance of hydraulic Concrete}

Concrete has low tensile strength and poor crack resistance. The concrete buildings in the water conservancy projects locate in special environment. Alternation of drying and wetting, current, corrosion and other complex factors aggravate the cracking of concrete in concrete structures of conservancy project. In conservancy project, concrete cracks may cause structural leakage, which seriously affect the performance of the structure and the normal play of engineering benefits, even lead to abandon the hydraulic structures. If we replace steel with carbon fiber or carbon fiber reinforced plastic (CFRP) to make carbon fiber reinforced concrete or CFRP concrete which can be used in the special position of water conservancy project, the strong 
corrosion resistance of carbon fiber materials will solve the problem of steel corrosion in reinforced concrete structure fundamentally, which will not only improves the performance, but also can prolong the service life of the structure, as well as reduce the maintenance cost. Research shows that when the carbon fiber composite materials are replaced with conventional steels, which have equal strength, the cost of carbon fiber composite materials is only half of the steel. This fully reflects the carbon fiber reinforcement can replace steel in conservancy project to reduce the cost. Adding of carbon fiber in concrete can play a significant role in strengthening the concrete matrix, resisting crack and increasing toughness[6][12]. Therefore, carbon fiber reinforced concrete can replace steel to be used in hydraulic concrete to improve its crack resistance and corrosion resistance.

\section{Use Carbon Fiber Polymer to Reinforce Hydraulic Concrete Structure}

Carbon fiber reinforcement is a new technology of structural reinforcement and strengthening researched and developed in the United States and Japan in recent years, which can make an effective reinforcement on the structure without increasing the structure load. At normal temperature, the common force integral structure of the carbon fiber polymer and the concrete is formed by using epoxy resin to plaster the directional placed carbon fiber fabric to the face of concrete, as shown in Fig. 2. Carbon fiber reinforced composite material has high strength, lightweight, good deformation adaptability and convenient to construct (can be constructed in the narrow space), therefore, carbon fiber polymers reinforcement technology has particularly good technical effect and economic benefit.
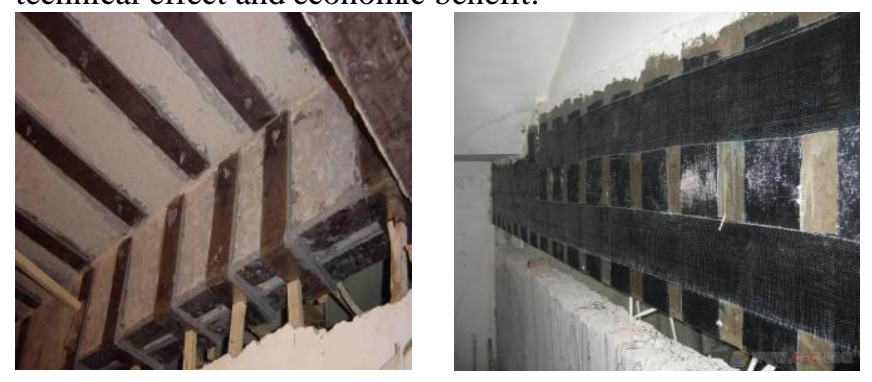

Figure 2. Concrete structure reinforced with CFRP

There is a thin wall multiple-arch dam [7] in Anhui Province, at elevation $80 \mathrm{~m}$ of certain arch section, arch barrel seam and ring building seam was cut, therefore, the arch integrity was destroyed and its bearing capacity was weakened, which formed a dangerous triangular arch block, seriously threatening the dam integrity and safety. The permeated water was blocked, and the dam concrete was reinforced, when the carbon fiber sheets were used for reinforcing the dam body seam. After repairing and reinforcing, the cracks of thin wall multiple-arch dam were relieved, dam integrity was restored and its structural bearing capacity was enhanced.

The spillway at right bank of one reservoir in Guangdong Province constructed in 2001, is in open structure [8]. At the beginning of September 2002, multiple penetrating cracks were found on the spillway weir body concrete, which destroyed the spillway integrity and resulted in hidden dangers. Survey indicated that the cracks existed on weir body concrete were caused by temperature stress. To ensure the spillway could run safely and stably, chemical grouting treatment of cracks, which use chemical grouting with epoxy resin grouting material that can be cured in water to repair the cracks, was adopted. High-strength carbon fiber sheets were applied to vertical cracks of concrete surface to block concrete surface cracks and ensure crack not opened. By such method, the spillway integrity was restored to meet design requirements and obtaining better reinforcing effects.

"635" hydro-junction trunk sluice [9] locates in Xinjiang Uygur Autonomous Region, through the first investigation, 36 cracks of about $117.2 \mathrm{~m}$ in length were found. 8 cracks of $30.8 \mathrm{~m}$ were in breast wall; 28 cracks were in wall at right bank of upper and lower reaches, all of which originated from inner side root of wall bottom and extended upward to certain height. As early as 2000 , the cracks were repaired and reinforced, but in 2003, water leakage was found in reinforced concrete breast wall. To ensure the project could run safely, carbon fiber sheets were decided to be used for repairing and reinforcing. The carbon fiber sheets can not only restrain deformation of concrete at cracks and reduce developing width of cracks, but also help surface seepage prevention within a certain scope. After repairing and reinforcing, under all kinds of loads during running, especially strong high and low temperature variations in northwest China, it can run safely. It is a successful application of carbon fiber reinforcing technology in repairing and reinforcing the mass concrete structures of hydraulic structure.

The JiangSu SanHe Sluice in Southeast corner of HongZe Lake is a control one in HuaiHe-ChangJiang Waterway with design flow of $12000 \mathrm{~m}^{3} / \mathrm{s}$ [10][12] which belongs to big type I according to classification and grading standard of hydraulic structures. When sluice was reinforced in 1968, 128 reinforced concrete bulkhead gate-lifting brackets were set at upper stream of sluice body. Because of deficient bracket design and poor construction quality, in 1998, peeling off, exposed reinforcing steel bar, cracks, etc. were found in bracket concrete. The cement mortar was poured for many times to repair and reinforce the bracket concrete structure, but hidden dangers still existed. In July 2004, SanHe Sluice Control Station reinforced the brackets with carbon fiber sheets, obtaining success. Compared with traditional common steel bonding method, such reinforcing method with carbon fiber sheets had apparent advantages in reinforcing characteristics (see Tab. 2). After being reinforced by carbon fiber sheets, SanHe sluice bulkhead gate lifting brackets get great improvement in bending resistance and shearing resistance than before.

In addition, the thermal conductivity of carbon fiber material is good (its thermal conductivity is 6 times more than that of plain concrete). Incorporation of carbon fiber can significantly improve the thermal conductivity, so as to reduce the temperature and strain of fiber reinforced concrete structural members. Carbon fiber in the fiber direction is 
opposite the coefficient of thermal expansion, when the fiber concrete component is heated, fiber shrinkages and makes pressure on concrete, fiber will be swelling deformation of concrete, thereby reducing the deformation of fiber reinforced concrete. In view of this, reasonable design of carbon fiber reinforced concrete and application in special parts of workshop of hydropower station can reduce high speed, high-pressure current action, as well as the vibration caused by concrete of the powerhouse. At the same time, it can be used to reduce the vibration and noise reduction of the buildings in hydraulic engineering by the power dissipation performance.

\section{CONCLUSIONS}

(1) With advantages of high strength, high elastic modulus, low density, high specific strength, resistance of heat and cold, anti-acid corrosion, small thermal expansion coefficient, large thermal conductivity coefficient etc., carbon fiber materials have been widely used in reinforcement of hydraulic engineering construction.

(2) Carbon fiber material used in special parts of hydraulic engineering buildings (such as different partitions) can improve performance, reduce cracks, improve the strength of concrete, increase the durability of hydraulic concrete, improve project efficiency, reduce project cost, maintenance cost and prolong service life of projects.

(3) The reinforced concrete structure corrosion has been a difficult problem in engineering field. Substituting carbon fiber reinforced plastic bar (CFRPB) for steel to form FRP reinforced concrete structure will solve the problem [13][14]. However, the current research and application of FRP reinforced concrete structure in China is still in its infancy, there is still a lot of work to be carried out.

\section{REFERENCES}

[1] Yang Hong, etc. Reinforcing technology of carbon fiber in dangerous reservoir. [M]. Beijing: China Water Conservancy and Hydropower Press, 2008: 3-16

[2] Zheng Zi-xiang, Zhang Xiu-li, etc. Application of Polypropylene Fiber Concrete in Faced Rockfill Dam of BaiXi Reservoir [J]. Hydroelectric power, 2002 (11).

[3] Lao Jian-weng. Construction of Polypropylene Fiber Concrete for the Second Stage of BaiXi Reservoir Dam [J]. East China Electric Power, 2002(1).

[4] Zheng Gong-ming. Application of Polypropylene Fiber Net in Repairing Overflow Surface of DaHeiTing Reservoir [J]. 2002 (2).

[5] Zhu Guan-mei, Yang Song-ling Experiment Study on Polypropylene Fiber Reinforced Concrete For Three Gorges Project. [J]. People of the Yangtze River,2002 (10).

[6] Zhang Ya-kun, Hou Li-li. Application of Fiber-Reinforced Concrete in Hydraulic Engineering [J]. Journal of Yangtze River Scientific Research Institute, 2012 (10): 114-117.

[7] Li Bao-chun. Technology Application and Quality Control of Carbon Fiber Structure Reinforcement [J]. Governance Huai, 2006 (8).

[8] He Yong-ri. Concrete Crack Treatment of a Reservoir spillway [J]. People's Pearl River, 2004 (4)

[9] Li Xin, Shi Ke-bin. Analysis of Cause and Treatment of Cracks on Parapets of the Main Intake Structures of the "635" Water Conservancy Project [J]. Hydroelectric power, 2006(3)

[10] Zhang Shi, Zhu Xiao-su, Rong Hai-bei. Application Of carbon for strengthenings of Sanbe Sluice. [J] Technology of Hydropower. , 2005 (5).

[11] Chen Wen, LAI Miao fa. Application of CFRP on Consolidation and Reconstruction Engineering in Nanjiang Reservoir [J]. Zhejiang Hydrotechnics, 2014 (11).

[12] Zhao Guo-fan, HUANG Cheng-kui. Research and Application of Fiber Reinforced Concrete [M]. Dalian: Dalian University of Technology Press, 1992: 256-259.

[13] Hou Li-li, Zhang Ya-kun. Finite Element Simulation on the Punching Process of FRP Reinforced Concrete Two-way Slabs [J]. Journal of Yangtze River Scientific Research Institute, 2014(5): 87-91.

[14] Zhang Ya-kun, HOU Li-li. Deformation of Fiber Reinforced Polymer Bar Concrete Slabs [J]. Journal of Yangtze River Scientific Research Institute, 2013(9): 106-109. 